\title{
Resistance of Melanesian Elliptocytes (Ovalocytes) to Invasion by Plasmodium knowlesi and Plasmodium falciparum Malaria Parasites In Vitro
}

\author{
Terence Hadley, Allan Saul, Gretel lamont, Diane E. Hudson, \\ Louis H. Miller, and Chev KIDSON, Laboratory of Parasitic Diseases, \\ National Institute of Allergy and Infectious Diseases, National Institutes of \\ Health, Bethesda, Maryland 20205; Queensland Institute of Medical \\ Research, Brisbane 4006, Australia
}

\begin{abstract}
A B S T R C T Erythrocytes from humans with Melanesian elliptocytosis are resistant to invasion by Plasmodium falciparum in vitro and epidemiological evidence suggests they may be resistant to $P$. vivax and $P$. malariae. We have examined the ability of $P$. knowlesi merozoites to invade Melanesian elliptocytes in vitro as a definitive means of examining these cells for resistance to invasion by malarial species with different receptor requirements. The Melanesian elliptocytes were highly resistant to invasion by $P$. knowlesi merozoites showing that the resistance associated with this erythrocyte variant lies at a level common to the invasion pathway(s) of $P$. falciparum and $P$. knowlesi. This makes Melanesian elliptocytosis unique as no other human erythrocyte variant has been shown to be resistant to invasion by both species.
\end{abstract}

\section{INTRODUCTION}

The relationship between human erythrocyte variants and resistance to malaria has been used in studying the basic biology (1) and epidemiology of malaria as well as human population genetics and the evolution of human erythrocyte variants (2). One such variant recently shown to afford protection from malaria is elliptocytosis in Melanesia and South East Asia. This variant has also been referred to in the literature as

Received for publication 27 September 1982 and in revised form 3 December 1982.
Melanesian ovalocytosis. Studies done in Papua New Guinea show that elliptocytosis is rare in the nonmalarious highlands and common in the malarious coastal lowlands (3), where it is found in some areas in $>20 \%$ of the population (4). Baer et al. (5) first proposed that it might confer resistance to malaria. Recently, it has been shown (6) that these Melanesian elliptocytes are resistant to invasion by Plasmodium falciparum in vitro.

Epidemiological data indicates that patients with elliptocytosis in Melanesia also have a lower parasitemia and frequency of infection with other human malarias, namely $P$. vivax and $P$. malariae (7). If $\mathrm{Me}-$ lanesian elliptocytes are relatively resistant to invasion by these parasites as well as by $P$. falciparum, this would indicate a defect common to the invasion pathway(s) of all of these parasites. Unfortunately, the problems in obtaining unequivocal evidence of resistance from epidemiological studies, the lack of methods for culture of $P$. vivax and $P$. malariae in vitro, and the consequent lack of knowledge concerning their receptor requirements preclude a conclusive result at the present time. However, since the primate malaria, $P$. knowlesi, can be cultured in vitro and since it is known to have different receptor requirements from $P$. falciparum (8), we have studied the attachment and invasion of Melanesia elliptocytes by this malarial parasite. Our study demonstrates that Melanesian elliptocytes are resistant to invasion by $\boldsymbol{P}$. knowlesi as well as by $P$. falciparum indicating that the resistance of these elliptocytes to malaria is at the 
level of a common pathway rather than a specific receptor defect.

\section{METHODS}

Blood samples. Elliptocytes were obtained from two Melanesians born in Papua New Guinea now residing in Brisbane, Australia. Elliptocyte sample 1 was from an individual with blood groups $A_{1}$, CcDee, kk, Fy $y^{a+b-}$, MNss, and $\mathrm{Le}^{\mathrm{a}-\mathrm{b}-}$. Elliptocyte sample 2 was from an individual with blood groups $A_{1}$, CcDee, kk, Fy $y^{a+b-}$, and MNss, Le $e^{a-b-}$.

Three normal samples were collected at the same time and handled identically. These were from individuals with the following blood groups: (a) $\mathrm{A}_{1}, \mathrm{CcDee}, \mathrm{kk}, \mathrm{Fy}^{\mathrm{a}-\mathrm{b}+}, \mathrm{Jk}^{\mathrm{a}-\mathrm{b}+}$, NNSs, Le $\mathrm{Le}^{\mathrm{a}-\mathrm{b+}} ;$ (b) O, ccee, kk, Fy $\mathrm{y}^{\mathrm{a}+\mathrm{b}-}, \mathrm{Jk}^{\mathrm{a}+\mathrm{b+}}, \mathrm{MNSs}, \mathrm{Le}^{\mathrm{a}-\mathrm{b+}}$; (c) $\mathrm{A}_{1}, \mathrm{CcDee}, \mathrm{kk}, \mathrm{Fy}^{\mathrm{a}+\mathrm{b}-}, \mathrm{NNss}, \mathrm{Le}^{\mathrm{a}+\mathrm{b}-}$.

All blood samples were collected in Brisbane and a portion of each was shipped to Bethesda, MD, where they arrived on ice. Assays with $P$. falciparum were done in Brisbane; assays done with $P$. knowlesi were done in Bethesda.

Invasion assays using $P$. knowlesi. Invasion assays were done as previously described (9). Briefly, erythrocytes infected with mature schizonts, about to rupture and reinvade were cultured at a concentration of $10^{6} / \mathrm{ml}$ with the erythrocytes to be tested at a concentration of $10^{7} / \mathrm{ml}$ in $0.5-\mathrm{ml}$ cultures in 16-mm diam tissue culture wells (Costar Data Packaging, Cambridge, MA). After $6 \mathrm{~h}$ incubation at $37^{\circ} \mathrm{C}$ invasion rates were determined by counting the number of rings (young parasites) per 1000 erythrocytes on blood films stained with Giemsa (Fisher Scientific Co., Fair Lawn, NY).

Invasion assays using $P$. falciparum. These were done on the same blood samples in Brisbane, as previously described (6). Briefly, schizont-infected erythrocytes at a concentration of $2 \times 10^{7} / \mathrm{ml}$ were mixed with fluorescein isothiocyanate (FITC) ${ }^{1}$-labeled test erythrocytes at a concentration of $2 \times 10^{8} / \mathrm{ml}$ in culture. After incubation for $16 \mathrm{~h}$, thin blood films were made, fixed in methanol, and stained with $50 \mu \mathrm{g} / \mathrm{ml}$ propidium iodide (Sigma Chemical Co., St. Louis, MO) in $0.2 \mathrm{M} \mathrm{NaCl}, 0.2 \mathrm{M}$ Tris/ $\mathrm{HCl}, \mathrm{pH} 8.3$. The invasion rate was determined by counting the number of rings per 1,000 FITC-labeled cells.

Attachment assay. P. knowlesi merozoites were obtained and assays for attachment were performed as previously described (10) using cytochalasin B (Aldrich Chemical Co., Milwaukee, WI) to stop merozoites at the attachment step of invasion.

Enzyme treatment of Melanesian elliptocytes. Elliptocytes and normocytes at a concentration of $3 \times 10^{8}$ cells $/ \mathrm{ml}$ were exposed to $1 \mathrm{mg}$ of trypsin-L-1-tosylamide-2-phenylethyl-chloromethyl ketone (Millipore Corp., Bedford, MA) for $30 \mathrm{~min}$ at $37^{\circ} \mathrm{C}$. These cells were then washed with 100 vol of culture medium with $1 \mathrm{mg} / \mathrm{ml}$ soybean trypsin inhibitor (Sigma Chemical Co.) followed by two washes with $100 \mathrm{vol}$ of culture medium. The cells were then suspended in culture medium with $10 \%$ fetal calf serum and tested for invasion. The effect of trypsin was confirmed by finding a $27 \pm 3.05 \%$ reduction in electrophoretic mobility.

\section{RESULTS}

Invasion by $P$. knowlesi. As shown in Table $I$ invasion of the Melanesian elliptocytes was markedly

\footnotetext{
${ }^{1}$ Abbreviation used in this paper: FITC, fluorescein isothiocyanate.
}

TABLE I

Invasion of Melanesian Elliptocytes and Normal Erythrocytes (Controls) by P. knowlesi and P. falciparum

\begin{tabular}{lccccc}
\hline & & \multicolumn{3}{c}{$\begin{array}{c}\text { P. knowlest } \\
\text { rings per 100 erythrocytes }\end{array}$} \\
\cline { 3 - 6 } & & $\begin{array}{c}\text { P. falciparum } \\
\text { rings per 100 }\end{array}$ & & \multicolumn{2}{c}{ Expt. 2 } \\
\cline { 3 - 6 } Sample & FITC-labeled erythrocytes & Expt. 1 & -tryp & +trypt \\
\hline Elliptocyte 1 & $0.25 \pm 0.08$ & 0.4 & 0.1 & 0.2 \\
Elliptocyte 2 & $0.11 \pm 0.11$ & 0.5 & 0.3 & 0.3 \\
Control 1 & $9.64 \pm 1.71$ & 20.6 & 7.9 & 8.1 \\
Control 2 & $4.57 \pm 2.33$ & 14.2 & 6.3 & 8.3 \\
Control 3 & $6.76 \pm 1.28$ & 17.9 & 7.7 & 9.2 \\
\hline
\end{tabular}

- For invasion assays with $\boldsymbol{P}$. falciparum target erythrocytes were labeled with FITC to distinguish them from the erythrocytes remaining in the preparation of schizont-infected cells.

$\downarrow+$ Tryp refers to trypsin-treated erythrocytes; -tryp refers to untreated erythrocytes.

reduced compared with that of controls. The few ring forms found may have represented invasion of the few remaining rhesus erythrocytes in our schizont preparation.

Invasion by $P$. falciparum. Invasion of the Melanesian elliptocytes was significantly less than invasion of the normocytic controls (Table I). Since the elliptocytes were labeled with FITC and thus distinguishable from uninfected donor cells, we can be sure that occasional elliptocytes were invaded by $P$. falciparum.

Enzyme treatment. Because Duffy negative $\left(\mathrm{Fy}^{\mathrm{a}-\mathrm{b}-}\right)$ human erythrocytes, which are resistant to invasion by $P$. knowlesi, become susceptible after treatment with trypsin (11), we tested the effect of trypsin treatment on invasion of elliptocytes. As shown in Table I, trypsin treatment had no effect on invasion by $P$. knowlesi merozoites.

Merozoite attachment. As shown in Table II attachment of $P$. knowlesi merozoites to elliptocytes was reduced in comparison to control human erythrocytes.

TABLE II

Attachment to Erythrocytes by P. knowlesi Merozoites

\begin{tabular}{cc}
\hline Sample & Percentage of merozoites attached \\
\hline Elliptocyte 1 & 0.9 \\
Elliptocyte 2 & 1.8 \\
Control 1 & 6.7 \\
Control 2 & 3.4 \\
Control 3 & 4.3 \\
\hline
\end{tabular}

- Attached merozoites were quantified by Smith interference microscopy by counting attached merozoites per 1,000 erythrocytes. 


\section{DISCUSSION}

Our data indicate that Melanesian elliptocytes are resistant to invasion by $P$. knowlesi merozoites. The only other human erythrocyte known with this degree of resistance is the Duffy negative phenotype $\left(\mathrm{Fy}^{\mathrm{a}-\mathrm{b}-}\right)$ (12). The Melanesian elliptocytes tested thus far were Duffy positive $\left(\mathrm{Fy}^{\mathrm{a}+\mathrm{b}-}\right)$ and unlike Duffy negative erythrocytes, these cells are not rendered susceptible to invasion by trypsin treatment. Therefore, the block to invasion is different from that of the Duffy negative erythrocyte.

The fact that these Melanesian elliptocytes are resistant to invasion by both $P$. knowlesi and $P$. falciparum makes these cells unique, as no other human erythrocyte to date has been shown to be resistant to both parasites. While the decreased attachment of $P$. knowlesi merozoites to Melanesian elliptocytes measured here is consistent with a receptor defect, previous studies have shown that $P$. knowlesi and $P$. fal ciparum have different receptor requirements (8). Trypsin treatment of human erythrocytes markedly reduces the invasion rate by $P$. falciparum but not by P. knowlesi. Chymotrypsin treatment at $100 \mu \mathrm{g} / \mathrm{ml}$, on the other hand, abolishes susceptibility to $P$. knowlesi but not to $P$. falciparum. Also, Duffy negative $\left(\mathrm{Fy}^{\mathrm{a}-\mathrm{b}-}\right)$ erythrocytes, which are resistant to invasion by $P$. knowlesi are susceptible to $P$. falciparum (8). $\mathrm{En}(\mathrm{a}-)$ cells, which lack glycophorin A, are relatively resistant to invasion by $P$. falciparum (11) but susceptible to $P$. knowlesi (8). Thus any explanation for the resistance of Melanesian elliptocytes to malaria must involve a mechanism common to the invasion pathway of species with different known receptor requirements. Several blood group antigens including the $I^{T}, I^{\mathrm{F}}, \mathrm{LW}$, $\mathrm{D}, \mathrm{C}, \mathrm{e}, \mathrm{S}, \mathrm{s}, \mathrm{u}, \mathrm{Kp}^{\mathrm{b}}, \mathrm{Jk}^{\mathrm{a}}, \mathrm{Xg}^{\mathrm{a}}, \mathrm{Scl}, \mathrm{En}^{\mathrm{a}}$ and $\mathrm{Wr}^{\mathrm{b}}$ antigens are depressed on Melanesian elliptocytes (13) and it is possible that one or more of these is associated with a membrane component important in the invasion pathway of both $P$. knowlesi and P. falciparum.

Another possible explanation for our findings would be that Melanesian elliptocytes possess a defect in some process modulating the availability of receptors during the attachment process. It is possible that the inability of Melanesian elliptocytes to deform sufficiently to allow juxtaposition of the erythrocyte and merozoite membrane would lead to inaccessibility of the receptors to all species of malaria. Melanesian elliptocytes are resistant to deformation with heating (6) and metabolic depletion (3). However, they do not show reduced deformability as measured in polycarbonate membrane filtration experiments (Lamont et al. Un- published results). Lateral mobility of membrane components in Melanesian elliptocytes has not been examined and it is possible that restricted lateral mobility of specific membrane components could also cause reduced binding of all species of malarial merozoites to Melanesian elliptocytes. As more knowledge of the abnormalities involved in Melanesian elliptocytes is acquired, insights might be gained into important molecular interactions necessary for invasion of erythrocytes by malarial parasites.

\section{REFERENCES}

1. Miller, L. H., F. M. McAuliffe, and S. J. Mason. 1977. Erythrocyte receptors for malaria merozoites. Am. J. Trop. Med. Hyg. 26: 204-208.

2. Luzzato, L. 1979. Genetics of red cells and susceptibility to malaria. Blood. 54: 961-976.

3. Castelino, D., A. Saul, P. Myler, C. Kidson, H. Thomas, and R. Cooke. 1981. Ovalocytosis in Papua New Guineadominantly inherited resistance to malaria. Southeast Asian J. Trop. Med. Public Health. 12: 549-555.

4. Amato, D. 1975. Elliptocytosis in Papua New Guinea. Proceedings of the 10th Annual Symposium Medical Society PNG (Port Moresby). p 140.

5. Baer, A., L. E. Lie-Injo, Q. B. Welch, and A. N. Lewis. 1976. Genetic factors and malaria in the Temuan. Am. J. Hum. Genet. 28: 179-188.

6. Kidson, C., G. Lamont, A. Saul, and G. T. Nurse. 1981. Ovalocytic erythrocytes from Melanesians are resistant to invasion by malaria parasites in culture. Proc. Natl. Acad. Sci. USA. 78: 5829-5832.

7. Serjeantson, S., K. Bryson, D. Amato, and D. Babona. 1977. Malaria and hereditary ovalocytosis. Hum. Genet. 37: 161-167.

8. Miller, L. H., J. D. Haynes, F. M. McAuliffe, T. Shiroishi, J. R. Durocher, and M. H. McGuinniss. 1977. Evidence for differences in erythrocyte surface receptors for the malarial parasites, Plasmodium falciparum and Plasmodium knowlesi. J. Exp. Med. 146: 277-281.

9. Miller, L. H., S. J. Mason, J. A. Dvorak, M. H. McGinniss, and I. K. Rothman. 1975. Erythrocyte receptors for ( $P$. knowlesi) malaria: Duffy blood group determinants. Science (Wash. DC). 189: 561-563.

10. Miller, L. H., M. Aikawa, J. G. Johnson, and T. Shiraishi. 1979. Interaction between cytochalasim B-treated malarial parasites and erythrocytes.. Attachment and junction formation. J. Exp. Med. 149: 172-183.

11. Pasvol, G., J. S. Wainscoat, and D. J. Weatherall. 1982. Erythrocytes deficient in glycophorin resist invasion by the malaria parasite Plasmodium falciparum. Nature (Lond.). 297: 64-66.

12. Mason, S. J., L. H. Miller, T. Shiroishi, J. A. Dvorak, and M. H. McGinniss. 1977. The Duffy blood group determinants: their role in the susceptibility of human and animal erythrocytes to Plasmodium knowlesi malaria. Br. J. Haematol. 36: 327-335.

13. Booth, P. B., S. Serjeantson, D. G. Woodfield, and D. Amato. 1977. Selective depressions of blood group antigens associated with hereditary ovalocytosis among Melanesians. Vox Sang. 32: 99-110. 